\title{
Deskripsi Pembelajaran di Pondok Pesantren Putri
}

\author{
Oleh: \\ Rohmatul Kholidah \\ (Pondok Pesantren Al Mahrusiyah Lirboyo Kediri)
}

\begin{abstract}
Abstrak
Tulisan ini bermaksud mendeskripsikan pembelajaran Marasah Diniyah putrid (Madin), Majelis Musyawatah Madrasah (M2M), dan Tartil Qur'an (TQ). Pendekatan yang digunakan dalam tulisan ini adalah penelitian kualitatif deskriptif. Teknik pengumpulan data dokumentasi, observasi, dan wawancara. Sedangkan untuk menganalisisnya penulis menggunakan tekhnik analisis reduksi data, penyajian data, dan verifikasi data. Hasil penelitian, Pembalajaran di Madin, M2M TQ Kota Kediri sangat dipengaruhi oleh peran ketelatenan para pengajar dalam kegiatan belajar mengajar di Kelas, serta kesiapan para siswi, menetapkan pembiasaan kedisiplinan siswi, dan menetapkan metode hukuman.
\end{abstract}

Kata Kunci: Deskripsi, Pembelajaran di Pondok Pesantren, Teori Belajar Behaviorisme

\begin{abstract}
This article intends to describe the learning Marasah Diniyah daughter (Madin), Assembly Musyawatah Madrasah (M2M), and Tartil Quran (TQ). The approach used in this paper is a descriptive qualitative research. Data collection techniques of documentation, observation, and interviews. As for the author uses analysis techniques to analyze data reduction, data presentation, and data verification. The results of the study, pembalajaran in Madin, M2M TQ of Kediri greatly influenced by the role diligence of the teachers in teaching and learning activities in the classroom, as well as the readiness of the students, habituation sets student discipline, and set the method of punishment.
\end{abstract}


Keywords: Description, Learning at boarding school, Learning Theory Behaviorism

\section{Pendahuluan}

Salah satu elemen pendidikan keagamaan di Indonesia adalah Pesantren yang merupakan lembaga pendidikan Islam, bersifat otonom, dan memiliki culture tersendiri di mana budaya pesantren akan bersifat mengikat bagi penghuninya. Pesantren sebagai salah satu lembaga pendidikan Islam tidak hanya mengintegrasikan ilmu-ilmu keislaman, namun lebih mendalam yaitu penanaman karakter-karakter patriotik juga diupayakan dalam kehidupan Pesantren. Santri (sebutan peserta didik dalam lingkungan pesantren) dibiasakan untuk hidup sederhana dan apa adanya, serta dilatih memiliki sifat pantang menyerah, tekun, jujur, disiplin, serta mengormati guru (Zulva, 2014). Model pembiasaan inilah yang kemudian menarik dikaji dalam sistem pembelajaran di Pondok Pesantren.

Nuroni Soyomukti (2010) menjelaskan mengenai proses pembelajaran pendidikan klasikal yang terdapat di Pondok Pesantren, bahwasanya: dalam konsep Pendidkan Tradisional Kuno, tidak ada teori yang dirumuskan secara koheren yang membahas kegiatan belajar dalam sistem Pendidikan Tradisional, akan tetapi Psikologi Behaviorisme memiliki pengaruh yang jelas dalam Pendidikan Tradisional, sedangkan Psikologi Kognitif tak banyak berpengaruh dalam model Pendidikan ini.

Salah satunya adalah yang terkait dengan masalah Belajar Tuntas (mastery learning) (Mahmud, 2007). Prakteknya, santri dinyatakan lulus ketika ia telah memenuhi persyaratan ketuntasan dalam serangkaian proses Pembelajaran di Pondok Pesantren. Jika dikaitkan dengan teori belajar, penganalisisan model pendekatan Pembelajaran di Pondok Pesantren mengarah pada tingkah laku (behavior) seorang pembelajar (santri) itu sendiri.

Pendekatan psikologis dalam proses pembelajaran di Pondok Pesantren terjadi diantara seluruh elemennya secara persuasif. Bertujuan memberikan dorongan yang mampu 
menggerakkan daya Kognitif, Afektif, serta Psikomotorik para santri (Mahmud, 2007).

Temuan penelitian terdahulu, yang berhasil peneliti himpun terkait teori behaviorisme. Sebagaimana penelitian dalam beberapa jurnal yang dilakukan oleh Izzatur Rusuli, "Refleksi Teori Belajar Behavioristik Dalam Perspektif Islam", Fera Andriyan, "Teori Belajar Behavioristik Dan Pandangan Islam Tentang Behavioristik", Pn. Yong Shu Lan, "Gabungan Pendekatan Konstruktivisme Dan Behaviorlisme Bagi Meningkatkan Prestasi Mata Pelajaran Sejarah Tingkatan Tiga”, dan dalam skripsi Rahma Desyani, "Telaah Unsur-Unsur Behavioristik Pada Pendekatan Dan Metode Behavioristik“.

Berdasarkan beberapa penelitian tersebut, ternyata belum terdapat penelitian yang berfokus pada analisis terhadap teori belajar behaviorisme dalam proses pembelajaran. Atas dasar inilah, peneliti termotivasi untuk melakukan penelitian penganalisisan teori behaviorisme dalam proses pembalajaran yang terpusat di pondok pesantren, mengingat pondok pesantren merupakan lembaga pendidikan islam yang kental akan sistem klasikkalnya dalam kehidupan kesehariannya.

Studi pendahuluan dan observasi terhadap Pembelajaran di Pondok Pesantren Putri Lirboyo Al Mahrusiyah Kediri', ditemukan indkasi-indikasi Pembelajaran yang mengarah pada tingkah laku (behavior) dari santri. Sebut saja proses Pembelajaran di lembaga-lembaga yang berada di dalamnya. Dalam hal ini, penulis memilih tiga lembaga yang akan dijadikan sebagai fokus pembahasan pembelajaran tingkah laku (behavior), tiga lembaga tersebut adalah Madrasah Diniyah, Majlis Musyawarah, dan Tadris Qur'an P3LAM kota Kediri.

Menjelang akan dilaksanakannya serangkaian Ujian Akhir Semester Genap P3LAM Kota Kediri, dari lembaga Madrasah Diniyah dan Tadris Qur'an, fenomena yang menarik dikaji dari proses Pembelajaran Semester Akhir ini adalah tingkah laku (behavior) dari para santri. Santri berlomba-lomba untuk dapat mengikutinya dengan cara

1 Selanjutnya, akan sering disebut P3LAM kota kediri. 
melengkapi persyaratan yang telah ditentukan oleh masingmasing lembaga.

Menurut Ketua Tadris Qur'an yang juga menjadi Siswi

Kelas 2 Aliyah Madrasah Diniyah, ia berkata:

Saat-saat ini memang sedang giat-giatnya para santri melakukan setoran, baik itu setoran tadris ataupun nadhom, termasuk saya juga yang sedang mengejar tarjet setoran nadhom ini. Lihat saja untuk menghadapi ujian semester genap ini, setiap ada waktu luang, pegangan santri sekarang itu kalau tidak jet tempur (juz amma) ya nadhom, apalagi untuk Kbm Tadris Qur'an yang memang akan berakhir, dan santri yang dapat mengikuti ujian kan memang santri yang telah tuntas dan dinyatakan lulus hafalannya dan mendapat rekomendasi dari para ustad ataupun ustadzahnya. Sama halnya juga ketika akan diselenggarakannya Ujian Madin, persyaratannya harus mendapat nilai minimal mutawasit ketika pelaksanaan muhafadhoh. Belum lagi mulai setahun yang lalu kan memang telah dilaksanakan Qiro'atul Kutub, yang juga menjadi persyaratan wajib para siswi untuk mengikuti Ujian Madin. Pokoknya, kalau sudah mendekati masamasa Ujian apalagi Ujian Kenaikan Kelas Semester Genap ini, sebentar lagi ini nanti juga akan kelihatan, disetiap sudut Pondok, dimanapun santri berada, disana yang ada adalah kegiatan santri untuk memenuhi persyaratan mengikuti serangkaian Ujian, seperti: nembel kitab, lalaran nadhom ataupun hafalan Tadris sesuai tingkatannya, dan belajar (memuthola'ah) materi-materi kitab yang akan diujikan. Dan anehnya, kegiatan-kegiatan santri seperti itu, hanya dapat di temukan ketika akan menghadapi Ujian saja." (Rohimah, 2016)

Dari data di atas, perilaku santri sangat tergantung pada stimulus atau rangsangan yang terjadi di dalam proses Pembelajaran, santri akan merespon dengan tingkah lakunya melalui stimulus yang diberikan dan stimulus ini nantinya yang dapat mempengaruhi daya kuat respon santri terhadap proses pembelajaran.

Melihat pemaparan Konteks Penelitian di atas maka penulis dapat mengambil fokus penelitian sebagai berikut: Bagaimana Pembelajaran di Madrasah Diniyah, Majlis 
Musyawaroh Madrasah Diniyah dan Tadris Qur'an P3LAM Kota Kediri?

\section{Hasil Penelitian Dan Pembahasan}

\section{Pembelajaran di Madin Putri P3LAM Kota Kediri}

Hasil observasi dan wawancara yang dilakukan peneliti di lembaga Madin Putri P3LAM Kota Kediri dapat diketahui bahwa, Sistem pembelajaran di Madin Putri P3LAM Kota Kediri terbagi menjadi 2, yaitu:

KBM ini belangsung 6 hari dalam seminggu kecuali hari jum'at, sedangkan waktu pelaksanaan KBM di Kelas Madin 1.30 (90 menit), dengan perincian prosedur sebagai berikut: Lalaran (15 menit), Roisan, Hafalan, Pembacaan materi, dan Penjelasan.

Pembelajaran di luar KBM kelas merupakan program penunjang proses pembelajaran yang telah dibentuk oleh lembaga Madin Putri P3LAM Kota Kediri. diantaranya: KBM Musyawah dan KBM Setoran, dan KBM Qiro'atul Kutub.

Hasil temuan terkait Madin Putri P3LAM Kota Kdiri bahwa, di Madin Putri P3LAM Kota Kdiri merupakan lembaga nonformal yang terstruktur rapi dan terkenal dengan pembiasaan kedisiplinannya dalam proses pembelajaran. ${ }^{2}$ Temuan ini sependapat dengan ungkapan Ustad Ahmad Shodiqin S.Pd.I yang mengatakan bahwa madin putri ini terkenal dengan pembiasaan disiplin siswi yang sangat kental. la mengatakan bahwa:

Pembelajaran yang tedapat dalam Madin P3LAM itu lebih mengacu pada pembiasaan kedisiplinan dari para siswi, hal ini bisa dilihat dari sistem yang diterapkan didalamnya yang lebih mengacu kepada pemberian hukuman langsung yang berbentuk kartu mperah ketika terdapat siswi yang tidak taat terhadap tata tertib madin, dan melakukan pelanggaran, seperti telat, berlaku kurang sopan, dan tidak berseragam lengkap ketika proses pembelajaran, dll (Shodiqin, 2016),

Sependapat dengan ungkapan di atas, Dewi Aisyah (siswi Madin Kelas 3A tsanawiyah, sekaligus bendahara Madin

2 Hasil Observasi di Lembaga Madin P3LAM Kota Kediri pada Sabtu, 27 Februari 2016 pukul 13.00-17.30 WIB. 
Putri P3LAM Kota kediri periode 2015-2016), ia menjelaskan tentang Madin Putri P3LAM Kota kediri, bahwasanya:

Di madin itu kedisiplinan sangat diterapkan, dan sejauh ini kedisplinan di Madin mengalahkan kedisiplinan yang berada di formal, contohnya ketika ujian madin, siswi dijaga ketat oleh pengurus madin, siswi dilarang keras untuk mencontek, jangankan untuk mencontek, menoleh saat mengerjakan soal saja sudah dikartu merah. Dan dari peraturan kesehariannya pun kedisiplinannya itu juga sangat diterapkan, bagi siapa saja yang tidak mentaati dan melanggar peraturan madin maka seketika itu juga akan diberikan hukuman yang berupa kartu merah (Aisyah, 2016).

Hasil wawancara diatas, menunjukkan bahwa, pembelajaran di lembaga Madin Putri P3LAM Kota Kediri lebih menekankan pada pembiasaan kedisiplinan siswi dalam mengikuti proses pembelajaran di lembaga madin putri P3LAM kota kediri.

Hasil temuan lain dari observasi dan wawancara yang dilakukan peneliti pada lembaga Madin Putri P3LAM Kota Kediri bahwa, dalam Proses pembelajarannya, tidak terlepas dari beberapa unsur sebagai pendukung yang saling berkaitan satu sama lain. ${ }^{3}$ Diantaranya: Pengajar, Peserta didik, dan Pengkajian Kitab.

\section{Pembelajaran Di Majlis Musyawarah Madrasah (M2M) Diniyah Putri P3LAM Kota Kediri}

Hasil observasi dan wawancara yang dilakukan peneliti di lembaga Majlis Musyawarah Madrasah (M2M) Diniyah Putri P3LAM Kota Kediri dapat diketahui bahwa, KBM M2M dilaksanakan 6 hari dalam seminggu kecuali hari kamis malam jum'at, pelaksanaanya 1 jam. Sedangkan Waktu Musyawarah dapat dibagi menjadi 2, yaitu: Musyawarah Malam, Dan Musyawarah Sore

Lembaga M2M ini dibentuk oleh Madin sebagai program penunjang belajar siswi dalam mengembangkan materi pelajaran yang diberikan pengajar di Kelas Madin Putri

\footnotetext{
${ }^{3}$ Hasil Observasi di lembaga Madin P3LAM Kota Kediri pada Sabtu, 27 Februari 2016 pukul 13.00-17.30 WIB.
} 
P3LAM Kota Kediri, dengan tugas mengkoordinir jalannya Musyawarah (diskusi) bersama pelajaran Madin dengan sistem dan sruktur sebagaimana dalam Prosedur pelaksanaanya. yang meliputi:

a. Lalaran (10 menit)

b. Musyawarah Kecil / Diskusi Kelompok (20 menit)

c. Musyawarah Bersama / Diskusi Ro'isan (30 menit)

Temuan peneliti terkait lembaga M2M, bahwasanya, lembaga $\mathrm{M} 2 \mathrm{M}$ selain mengkoordinir jalannya musyawarah hasil belajar siswi di kelas madin, M2M memiliki programprogram yang dilaksanakan sejak awal tahun KBM madin hingga akhir ujian semester genap madin. Sebagaimana ungkapan Ustad Miftahuddin (Mustahiq 3 Aliyah sekaligus Ro'is Am M2M periode 2015-2016), ia mengungkapkan bahwa,

M2M itu merupakan lembaga yang mengurusi belajar para siswi Madin yang pelaksaannya itu sangat sistematis, sedangkan dari segi tatanannya (administrasinya), lembaga ini tersusun sangat rapi menjalankan tugasnya dalam rangka menyukseskan program-program Madin yang dimulai sejak awal tahun ajaran sampai akhir tahun KBM madin, diantaranya mulai dari Mengadakan Diklat Keroisan, Mengusahakan Perlengkapan Musyawarah, Mengkoordinatori Pelaksanaan Muhafadhoh baik Muhafadhoh Sugro (Mingguan) atau Muhafadhoh Kubro (Akhirusannah), Mengadakan Jadwal Pengontrolan Dan Penilaian Musyawaroh, serta Mengadakan dan Menentukan Siswi Teladan bagi Masing-Masing Kelas. Semuanya tadi merupakan program-program yang terdapat di lembaga $\mathrm{M} 2 \mathrm{M}$ yang masing-masing dari setiap program tersebut telah tersusun sedemikian rapi dalam pelaksanaanya (Miftahuddin, 2016).

Temuan lain yang berhasil peneliti himpun terkait lembaga $M 2 M$, bahwa $M 2 M$ ini merupakan lembaga di bawah naungan Madin yang dibentuk sebagai penunjang proses pembelajaran di Madin yang terstuktur rapi serta memiliki beberapa program yang sangat berperan dalam proses pembelajaran di Madin Putri P3LAM Kota Kediri. Sedangkan prosedur pelaksanaannya sangat dipengaruhi oleh beberapa unsur sebagai pendukung dalam proses 
pembelajarannya, diantaranya: peserta, pengurus, dan pengajar.

\section{Pembelajaran di Tadris Qur'an P3LAM Kota Kediri}

Dari hasil observasi yang dilakukan peneliti di lembaga TQ bahwa, KBM Pembelajaran di TQ terbagi menjadi 2 waktu, ${ }^{4}$ yaitu:

\section{a. KBM Pagi (KBM Tingkat l'dadiyah dan Ulya l-II)}

$\mathrm{KBM}$ ini berlangsung 5 hari dalam seminggu kecuali hari ahad dan jum'at, yang dilaksanakan selama 1 jam, sedangkan untuk waktu pelaksanaannya 15 menit setelah selesai sholat shubuh. Dengan sistem halaqoh, para siswi yang terdiri dari 13 sampai 18 orang melingkar mengelilingi pengajar sedangkan Prosedur pelaksanaannya:

1) Murotalan Wajib Bersama

2) Murotalan Pertingkatan

3) Hafalan, Sorogan, dan Materi.

\section{b. KBM Malam (KBM tingkatan Ulya III)}

KBM ini dikhususkan bagi siswi TQ tingkat Ulya III, yang sebagian dari siswi tersebut merupakan para siswi hafidhoh (sebutan untuk siswi penghafal qur'an), sedangkan sebagian lain adalah siswi yang telah mendapatkan gelar khotimat sab'ul munjiyat atau siswi yang telah lulus pada seleksi ujian kenaikan kelas tingkat ulya 11.5

Waktu, tempat, dan prosedur pelaksanaanya sedikit berbeda, yaitu sesuai kebijakan dari para pengajarnya. Sebagaimana ungkapan nur Rohimah siswi tingkat Ulya III sekaligus ketua TQ periode 2015-2016, yang mengungkapkan terkait KBM tingkat Ulya III, ia mengatakan bahwa:

Untuk Tingkatan Ulya III itu sistemnya sedikit berbeda, soalnya kan ngajinya di neng-nengnya langsung, karena sekarang beliau-beliaunya kan berada di Ngampel, KBMnya itu ketika beliau rawuh, dari kita sendiri nggak bisa memastikan kapan beliau-beliau itu rawuhnya, yang pasti dari

${ }^{4}$ Hasil Observasi di lembaga TQ P3LAM Kota Kediri pada Sabtu, 12 Maret 2016 pukul 19.00-19.30 WIB.

${ }^{5}$ Hasil observasi saat KBM malam TQ pada Sabtu, 12 Maret 2016 pukul 19.00-19.30 WIB. 
beliau-beliaunya itu bisa rawuh dan melaksanakan $\mathrm{kbm}$ itu pada malam hari, waktunya ketika setelah sholat magrib (saat KBM M2M berlangsung), jadi setiap malam itu harus ada beberapa siswi yang standbay lah untuk menyiapkan lokal dan nungguin beliau-beliau rawuh, biasanya ketua kelasnya, terus kan ada yang hafalan juga, biasanya yang hafalanhafalan itu nggunain waktu lalaran dan kelompokan ketika musyawaroh untuk ngelalar, kalo sampek bel kero'isan nengnengnya itu belum rawuh, maka para siswi kembali ke kelasnya untuk melaksanakan kbm musyawaroh karena dari pengurus $\mathrm{M} 2 \mathrm{M}$ sendiri memberikan izin hanya sampai bel kero'isan berbunyi, ketika itu semua siswi sudah harus ada dikelas untuk mengikuti kbm musyawaroh, dan yang nungguin neng-nengnya itu biasanya dilanjutkan oleh ustadzah-ustadzah madin yang ngaji di neng-nengnya (Rohimah. 2016).

Berdasarkan Temuan dari observasi dan wawancara yang berhasil peneliti himpun terkait pembelajaran di TQ, bahwa terdapat beberapa unsur pendukung dari proses pembelajaran di TQ, diantaranya: Pengajar, Siswi, dan Takhtiman TQ.

\section{Pembahasan}

Analisis teori behaviorisme pembelajaran di Madin Putri P3LAM Kota Kediri

Sistem Pembelajaran di Madin Putri P3LAM Kota Kediri mengacu kepada pembiasaan kedisiplinan para santri terhadap tata tertib dalam proses pembelajaran. Hal ini sesuai dengan teori belajar Classic conditioning yang di kemukakan oleh Ivan Petrovich Pavlov. yang menyatakan bahwa, proses pembelajaran perilaku individu yang dapat dikondisikan, karena Belajar merupakan upaya untuk mengkondisikan suatu perilaku (respon) siswi terhadap suatu pembelajaran. Sedangkan penerapan dalam proses pembelajaran di Madin P3LAM Kota Kediri menggunakan metode hukuman yang berupa Kartu Merah (hukuman langsung). Hal ini serupa dengan teori belajar Contiguous Conditioning Edwin $\mathrm{R}$. Guthrie, ia mengungkapkan bahwa, dalam proses pembelajaran harus disertai dengan adanya pemberian hukuman. sedangkan ketepatan waktu dalam pemberian 
hukuman sangat berpengaruh pada respon siswi (tingkah laku) yang akan muncul dalam proses pembelajaran.

Respon santri terhadap keberadaan bahwa madin merupakan kebutuhan bagi para siswi dalam mengkaji kitab kuning sebagai bekal di masyarakat nanti. Hal ini senada dengan teori Systematic Behavior yang dielopori oleh Clark Hull, ia mengungkapkan bahwa, hasil belajar siswi juga dipengaruhi oleh teori evolusi yang dikembangkan oleh Charles Darwin, dimana semua fungsi tingkah laku (respon) bermanfaat terutama untuk menjaga kelangsungan hidup manusia. Oleh sebab itu, kebutuhan biologis dan pemenuhan kebutuhan biologis adalah penting dan menempati posisi sentral dalam seluruh kegiatan manusia. Keaktifan para siswi juga dipengaruhi oleh peran keaktifan para pengajar tertebih seorang ustad yang aktif di kelas. Teori behavioris yang sepadan dengan temuan peneliti adalah teori Skinner, ia berpendapat bahwa, manusia atau hewan dalam proses belajar sangat di pengaruhi oleh pemberian tingkah laku khusus (stimulus khusus) akan menghasilkan suatu akibat atau konsekuensi yang khusus juga.

\section{Analisis teori behaviorisme pembelajaran di M2M Putri P3LAM Kota Kediri}

Sistem pembelajaran di lembaga M2M P3LAM Kota Kediri sangat dipengaruhi oleh kesadaran para siswi yang nantinya sangat berpengaruh dalam kesiapan para siswi dalam proses pembelajaran di lembaga M2M Kota Kediri. Hal ini serupa dengan hukum kesiapan (Law of Readiness) dalam teori throndeks yang mengungkapkan bahwa, keberhasilan belajar seseorang sangat bergantung dari ada atau tidaknya kesiapan siswi dalam belajar. Selain itu di lembaga M2M juga menerapkan pembisaan kedisiplinan para santri dalam mentaati tata tertib di lembaga $M 2 M$. Hal ini sesuai dengan teori belajar Classic conditioning oleh Ivan Petrovich Pavlov. yang menyatakan bahwa, proses pembelajaran perilaku individu yang dapat dikondisikan, karena Belajar merupakan upaya untuk mengkondisikan suatu perilaku (respon) siswi terhadap suatu pembelajaran. Sedangkan penerapan dalam proses pembelajaran di Madin P3LAM Kota Kediri 
menggunakan metode hukuman yang berupa Kartu pink (hukuman langsung). Hal ini serupa dengan teori belajar Contiguous Conditioning Edwin R. Guthrie, ia mengungkapkan bahwa, dalam proses pembelajaran harus disertai dengan adanya pemberian hukuman. sedangkan ketepatan waktu dalam pemberian hukuman sangat berpengaruh pada respon siswi (tingkah laku) yang akan muncul dalam proses pembelajaran. Serta peran pengajar dalam pengontrolan musyawaraoh sangatlah dominan yaitu sebagai penyemangat para siswi dalam pembelajaran di lembaga M2M. Teori behavioris yang sepadan dengan temuan peneliti adalah teori Skinner, ia berpendapat bahwa, manusia atau hewan dalam proses belajar sangat di pengaruhi oleh pemberian tingkah laku khusus (stimulus khusus) akan menghasilkan suatu akibat atau konsekuensi yang khusus juga.

\section{Analisis teori behaviorisme pembelajaran di TQ Putri P3LAM Kota Kediri}

Proses pembelajaran di lembaga M2M P3LAM Kota Kediri, sangat dipengaruhi oleh ketelatenan pengajar dalam proses pembelajaran di kelas. Hal ini serupa dengan teori Operant Conditioning dalam pembelajaran yang dicetuskan oleh skinner, bahwa, manusia atau hewan dalam proses belajar sangat di pengaruhi oleh pemberian tingkah laku khusus (stimulus khusus) yang akan menghasilkan suatu akibat atau konsekuensi yang khusus juga. Namun disisi lain, kesadaran siswi juga sangat berperan dalam proses pembelajaran. Hal ini sesuai dengan hokum kesiapan (Law of Readiness) dalam teori throndeks yang mengungkapkan bahwa, keberhasilan belajar seseorang sangat bergantung dari ada atau tidaknya kesiapan siswi dalam belajar.

Sistem pembelajaran di TQ menganut pembiasaan kedisiplinan dari para santri, hal ini sesuai dengan teori Classic conditioning Pavlov, yang menyatakan bahwa, proses pembelajaran perilaku individu dapat dikondisikan, karena Belajar merupakan upaya untuk mengkondisikan suatu perilaku (respon) siswi terhadap suatu pembelajaran. Sedangkan dalam proses pembelajarannya juga menetapkan metode hukuman bagi siswi yang melakukan pelanggaran di 
kelas ataupun melanggar tata tertib TQ. Hal ini serupa dengan teori belajar Contiguous Conditioning Edwin R. Guthrie, ia mengungkapkan bahwa, dalam proses pembelajaran harus disertai dengan adanya pemberian hukuman. sedangkan ketepatan waktu dalam pemberian hukuman sangat berpengaruh pada respon siswi (tingkah laku) yang akan muncul dalam proses pembelajaran.

\section{Penutup}

\section{Kesimpulan}

1. Pembelajaran di lembaga Madin Putri P3LAM Kota Kediri mengacu pada pembiasaan kedisiplinan para siswi dalam mentaati tata tertib baik di luar ataupun di dalam kelas ketika KBM Madin berlangsung, dengan menerapkan metode hukuman langsung yang berupa pemberian kartu merah bagi para siswi yang melanggar tata tertib. Sedangkan bagi para siswi, keberadaan Madin Putri P3LAM Kota Kediri merupakan kebutuhan mereka sebagai bekal di masyarakat, dan dalam proses pembelajarannya sangat di pengaruhi oleh peran keaktifan para pengajar dalam proses pembelajaran.

2. Pembelajaran di lembaga M2M P3LAM Kota Kediri sangat dipengaruhi oleh kesadaran para siswi, serta peran keaktifan para pengajar terlebih seorang ustad dalam kegiatan pengontrolan harian. Sedangkan sistem yang dianut dalam proses pembelajaran di lembaga $M 2 M$ adalah pembiasaan kedisiplinan para siswi, yang dalam penerapannya menggunakan metode hukuman langsung yang berupa kartu pink bagi para siswi yang melanggar tata tertib selama KBM berlangsung.

3. Pembelajaran di lembaga TQ P3LAM Kota Kediri sangat dipengaruhi oleh peran ketelatenan para pengajar dan kesadaran para siswi dalam proses pembelajaran di kelas. Sedangkan sistem pembelajarannya menganut pembiasaan kedisiplinan para siswi dengan menerapkan metode hukuman langsung yang berupa teguran, dan takziran bagi para siswi yang melanggar tata tertib selama proses pembelajaran. 


\section{Saran-Saran}

1. Bagi Pengajar.

Dihimbau bagi para pengajar agar lebih aktif di kelas terutama dalam memberikan semangat, motivasi, dan dorongan kepada para siswi agar selalu meningkatkan keaktifan dalam proses pembelajaran.

2. Bagi Peserta Didik.

Dihimbau agar para siswi lebih aktif dalam proses pembelajaran di lembaga-lembaga pendidikan di P3LAM Kota Kediri, terutama di lembaga pendidikan nonformal, karena pendidikan nonformal sangatlah penting untuk bakal para santri di kehidupan bermasyarakat nanti.

3. Bagi Lembaga-Lembaga Pembelajaran di P3LAM Kota Kediri.

Untuk meningkatkan mutu serta kualitas dalam pembelajaran, Dihimbau bagi segenap kepengurusan lembaga-lembaga pembelajaran di P3LAM Kota Kediri terutama lembaga pembelajaran nonformal untuk lebih meningkatkan kepeduliannya terhadap kedisiplinan dan semangatnya, baik untuk diri sendiri terkhusus untuk para siswi dalam proses pembelajaran.

4. Bagi Peneliti Selanjutnya.

Agar menyeimbangkan penelitian ini. Dihimbau bagi peneliti-peneliti selanjutnya untuk melakukan penelitian yang berfokus pada peserta didik santri putra. 


\section{Daftar Pustaka}

Aisyah, Dewi, Wawancara dengan (Siswi Madin Kelas 3A Tsanawiyah sekaligus Bendahara Madin P3LAM Periode 2015-2016, dan Ustadzah Ulya I C), di kantor P3LAM Kota Kediri pada tanggal 5 april 2016 pukul 09.30-10.00 WIB.

Andriyani, Fera. "Teori Belajar Behavioristik Dan Pandangan Islam Tentang Behavioristik", Syaikhuna Jurnal Pendidikan Dan Pranata Islam, Edisi 10 Nomor 2 Maret 2015.

Dhofier, Zamakhsyari. Tradisi Pesantren Studi Pandangan Hidup Kyai Dan Visinya Mengenai Masa Depan Indonesia Edisi Revisi, Jakarta: LP3ES, 2015.

Innecke Kartika W.W. Dkk, "Makalah Teori-Teori Pendidikan”, Diarsipkan Oleh Pls Um Untuk Imadiklus.Com. April, 2011.

Mahmud. Model-Model Pembelajaran Di Pondok Pesantren, Tanggerang: Media Nusantara 2007.

Miftahuddin, Wawancara dengan (Mustahiq Kelas 3 Aliyah sekaligus Ro' is Am M2M periode 2015-2016) di Pondok baru P3LAM 1 kota kediri pada tanggal 27 april 2016 pukul 17.00-17.30 WIB.

Observasi di lembaga Madin P3LAM Kota Kediri pada Sabtu, 27 Februari 2016 pukul 13.00-17.30 WIB.

Observasi di lembaga TQ P3LAM Kota Kediri pada Sabtu, 12 Maret 2016 pukul 19.00-19.30 WIB.

Observasi saat KBM malam TQ P3LAM Kota Kediri pada Sabtu, 12 Maret 2016 pukul 19.00-19.30 WIB. 
Rohimah, Nur, Wawancara dengan (siswi tingkat Ulya III sekaligus Ketua Tadris Qur'an) Di Ruang Tamu Pondok, Pada Senin, 14 Maret 2016 Pukul 07.30-08.00 WIB).

Rusuli, Izzatur. "Refleksi Teori Belajar Behavioristik Dalam Perspektif Islam", Jurnal Pencerahan Stain Gajah Putih Takengon Aceh Tengah Volume 8, Nomor 1, Juli Desember 2014.

Samsurrohman. "Pesantren Dan Tantangan Arus Global (Dakwah Pesantren Di Era Globalisasi)”. Jurnal Al-Qalam Unsiq Jawa Tengah Di Wonosobo, Vol.XIII, 2009.

Sanyata, Sigit. "Teori Dan Aplikasi Pendekatan Behavioristik Dalam Konseling”, Jurnal Paradigma, No. 14 Th.VII, Juli 2012.

Saragih, Raijon. "Pengaruh Penerapan Metode Edwin Guthrie Terhadap Kemampuan Mengapresiasi Cerpen "Namaku Dimas Oleh Kusniaty Kelas X Sma Gkpi Padang Bulan Medan 2012/2013". Seminar Pendidikan Sejarah Dan Geografi 2013, Ums, 29 - 30 Ogos 2013.

Shodiqin, Ahmad, Wawancara dengan (ustad kelas 3B Tsanawiyah) di Ruang Tamu P3LAM 1 Kota Kediri pada Rabu, 30 Maret 2016 pukul 21.30-22.00 WIB.

Soyomukti. Nuroni, Teori-Teori Pendidikan, Yogyakarta: ArRuzz Media, 2010.

Wibowo, A.M, dan Yusriati. "Standarisasi Penguasaan Kitab Kuning Di Pondok Pesantren (Studi Pada Madrasah Salafiyah Pesantren As-Salafiyah Mlangi, Sleman Dan Pesantren Al-Munawwir Krapyak Bantul Diy)”, Jurnal Al-Qalam Vol.XIII, 2010).

Yakin, Nurul. "Studi Kasus Pola Manajemen Pondok Pesantren Al-Raisiyah Di Kota Mataram", Ulumuna Jurnal Studi Keislaman, Volume 18 Nomor 1 Juni 2014. 
Zaini, Rifnon. "Makalah Studi Atas Pemikiran B.F Skinner Tentang Belajar", Diarsipkan Oleh Pls Um Untuk Imadiklus.Com. 2013

Zulva, Ngindiana. "Sejarah Taḥizuul Quran Pondok Pesantren Al Quran Nurul Huda Singosari Malang Tahun 19732007," E-Journal Pendidikan Sejarah Jurusan Pendidikan Sejarah, Fakultas Ilmu Sosial Universitas Negeri Surabaya Volume 2, No. 3, Oktober 2014. 